\title{
Antileukemic Agent
}

National Cancer Institute

\section{Source}

National Cancer Institute. Antileukemic Agent. NCI Thesaurus. Code C75574.

Any substance that treats, prevents, or inhibits the development of leukemia. 